\title{
OCEAN SURFACE WAVES: THEIR PHYSICS AND PREDICTION
}


Series Editor-in-Chief

Phillp L-F Liu (Comell University)

Vol. 1 The Applied Dynamics of Ocean Surface Waves by Chiang $C$ Mei (MIT)

Vol. 2 Water Wave Mechanics for Engineers and Scientists by Robert $G$ Dean (Univ. Florida) and Robert A Dalrymple (Univ. Delaware)

Vol. 3 Mechanics of Coastal Sediment Transport by Jergen Fredsere and Rolf Deigaard (Tech. Univ. Denmark)

Vol. 4 Coastal Bottom Boundary Layers and Sediment Transport by Peter Nielsen (Univ. Queensland)

Vol. 5 Numerical Modeling of Ocean Dynamics by Zygmunt Kowalik (Univ. Alaska) and T S Murty (Inst. Ocoan Science, BC)

Vol. 6 Kalman Filter Method in the Analysis of Vibrations Due to Water Waves by Piotr Wilde and Andrzej Kozakiewicz (Inst. Hydroengineering, Polish Academy of Sciences)

Vol. 7 Physical Models and Laboratory Techniques in Coastal Engineering by Steven A. Hughes (Coastal Engineering Research Center, USA)

Vol. 8 Ocean Disposal of Wastewater by lan $A$ Wood (Univ. Canterbury), Robert $G$ Bell (National Institute of Water \& Atmospheric Research, New Zealand) and David L Wilkinson (Univ. Now South Wales)

Vol. 9 Offshore Structure Modeling by Subrata K. Chakrabarti (Chicago Bridge \& Iron Technical Services Co., USA)

Vol. 10 Water Waves Generated by Undenwater Explosion by Bemard Le Méhauté and Shen Wang (Univ. Miami)

Vol. 11 Ocean Surface Waves; Their Physics and Prediction by Stanislaw R Massel (Australian Inst. of Marine Sci)

Forthcoming titles:

Water Waves Propagation Over Uneven Bottoms by Maarten $W$ Dingemans (Delft Hydraulics)

Tsunami Run-up by Philip L-F Liu (Comell Univ.), Costas Synolakis (Univ. Southern Califomia), Harry Yeh (Univ. Washington) and Nobu Shuto (Tohoku Univ.) 
Advanced Series on Ocean Engineering - Volume 11

\section{OCEAN SURFACE WAVES: THEIR PHYSICS AND PREDICTION}

\section{Stanisław R. Massel}

Australian Institute of Marine Science Australia

\section{Noworld Scientific}




\title{
Published by
}

World Scientific Publishing Co. Pte. Ltd.

5 Toh Tuck Link, Singapore 596224

USA office: 27 Warren Street, Suite 401-402, Hackensack, NJ 07601

UK office: 57 Shelton Street, Covent Garden, London WC2H 9HE

\author{
Library of Congress Cataloging-in-Publication Data \\ Massel, Stanislaw R. \\ Ocean surface wave : their physics and prediction / Stanishlaw R. \\ Massel. \\ p. cm. - (Advanced series on ocean engineering : v. 11) \\ Includes bibliographical references and indexes. \\ ISBN 9810216866 -- ISBN 9810221096 (pbk) \\ 1. Ocean waves. I. Title. II. Series. \\ GC211.2.M37 1996 \\ $551.47^{\prime} 02--d c 20$ \\ 95-18642 \\ CIP

\begin{abstract}
British Library Cataloguing-in-Publication Data
A catalogue record for this book is available from the British Library.
\end{abstract}

First published 1996

Reprinted 1998, 2005

Copyright $\odot 1996$ by World Scientific Publishing Co. Pte. Ltd.

All rights reserved. This book, or parts thereof, may not be reproduced in any form or by any means, electronic or mechanical, including photocopying, recording or any information storage and retrieval system now known or to be invented, without written permission from the Publisher.

For photocopying of material in this volume, please pay a copying fee through the Copyright Clearance Center, Inc., 222 Rosewood Drive, Danvers, MA 01923, USA. In this case permission to photocopy is not required from the publisher. 


\section{To my wife Barbara and children Andrzej, Magdalena and Bartosz}


This page is intentionally left blank 


\section{Preface}

Surface waves are one of the most obvious phenomena, almost constantly present on the surface of any water basin, such as ponds, lakes, rivers, artificial reservoirs, seas and oceans. The first studies on waves concentrated on the ideal, regular wave forms and resulted in a formulation of basic principles of surface wave mechanics. Regular waves can be considered only as a very crude approximation to real ocean waves. Modern marine science and ocean engineering practice need a more realistic representation of the ocean surface.

In the 1940s and '50s substantial progress in the theory of random functions and mathematical statistics provided powerful mathematical tools for a description of ocean waves as random phenomena. The first results of such studies were summarized by Kinsman in his book published thirty years ago.

Recent advances in instrument design and in data handling have allowed sampling of the ocean at rates and on scales hitherto inaccessible. Widespread use of high-speed computers has provided theoreticians with powerful tools and has made possible great improvement in the analysis of experimental data.

In the last three decades, numerous fundamental results were achieved and documented in hundreds of papers, distributed in many journals. However, at the same time, only a few books dedicated totally or partly to wind-induced waves were published. Several books on wind waves were also published in Russia, but due to the language barrier, these books are almost totally unknown among the Western scientific community. All published books fall into two distinct groups: those oriented towards classic oceanography, and those of an engineering nature. However, at the present time, the gap between oceanography, and coastal and ocean engineering, is becoming narrower in the sense that the discoveries in oceanography are transmitted almost immediately to practical applications in marine engineering.

The philosophy of the close link between ocean physics and ocean engineering is adopted in this book, which offers a very comprehensive and updated discussion of the fundamental scientific concepts of ocean wave mechanics and their practical applications. It is hoped that the very broad picture of ocean waves, given in the book, may provide some inspiration to new efforts and new solutions.

The book has two main objectives. The first is to provide a comprehensive review of the present understanding of the physics of ocean waves and their statistical and spectral description. The second objective is to provide a basic description of the 
viii

prediction models which can be used in ocean and coastal engineering, and in applied oceanography.

In order to achieve both of these objectives, the evolution of the scientific efforts in ocean wave physics during the last forty years is reviewed. Stochastic and probabilistic terminology is introduced, and the basic statistical and spectral properties of ocean waves are developed and discussed in detail.

Moreover, the book deals with practical prediction methods for waves in deep ocean and coastal zones, in island archipelagoes and coral reefs. Simple as well as very sophisticated methods are presented. The long-term evaluation of ocean wave parameters for design purposes are given and measurement techniques, including satellite applications and methods of wave data processing, are discussed.

This book is intended as a handbook for professionals and researchers in the areas of ocean and coastal engineering, physical oceanography, applied physics and as a useful book for graduate students in these fields. It should help bridge the gap between general texts on mathematical statistics and random processes and more descriptive texts on ocean engineering and oceanography.

The reader is assumed to have a working knowledge of calculus, and the analysis of the time series as well. A basic knowledge of hydrodynamic concepts would be helpful, although those subjects are reviewed shortly in the initial chapters of the book.

While the fundamental concepts of ocean wave physics are given in great detail, some advanced topics are only overviewed. However, an index and many cross references are provided in order to make the book more efficient as a handbook. The book's structure can be summarized as follows:

Chapter 1 discusses the basic assumptions and approaches to the description of ocean waves. The fundamentals of time series and spectra are discussed in detail.

Chapter 2 provides a brief description of the airflow over the ocean surface. This is followed by a presentation of the basic wave generation models. In particular, the various implementations to the classical Phillips-Miles model are considered. The spectral representations of wave energy balance, which are extensively used in the following chapters, are also discussed.

In Chapter 3 emphasis is placed on the various representation of ocean wave spectra and their usefulness for engineering and oceanographic applications.

In Chapter 4 a comprehensive and updated overview of the statistical properties of ocean waves is given. Topics include probability distributions for all surface wave parameters, as well as wave-induced velocities and pressure. For the particular ocean region (deep water, shallow water, surf zone etc.), corresponding wave statistics are identified.

Chapter 5 deals with wave prediction methods in deep water. First, the basic physical processes responsible for wave behaviour in the deep ocean are discussed. Topics include atmospheric forcing, nonlinear interactions between spectral components and wave energy dissipation. This is followed by a presentation of various 
forecasting methods. Besides the sophisticated prediction methods of first, second and third generation models, more simple empirical methods are also discussed.

Chapter 6 deals with ocean waves in finite water depth. The basic physical processes involved in wave motion include wave refraction, diffraction, reflection, nonlinear interactions and wave energy dissipation. As in Chapter 5, wave prediction methods are treated extensively.

Wave mechanics and wave forecasting techniques for island archipelagoes and coral reefs are still rather poorly known. Chapter 7 presents the basic methods for the evaluation of wind-induced waves in such environments. Emphasis is placed on the transformation, scattering and dissipation processes at islands and coral reefs.

Chapter 8 focuses on the prediction of design wave parameters using long-term statistics principles. First, the available visual observations and instrumental data are reviewed, and then the probability densities for extreme values are discussed. Some information on the 'geography' of extreme waves is also given.

Chapter 9 overviews wave measurement techniques and methods for wave data processing. Satellite wave detection techniques, as well as the more traditional techniques (wave staffs, wave buoys etc.), are discussed.

A large list of references, symbols and notation, as well as subject and author indexes are included in the book. For convenience, the titles of non-English papers are given in the original transcript, as well as in the English translation.

I apologize for the inevitable errors which may occur in this book, despite my efforts to eliminate them. Please bring these errors to my attention.

I would like to express my thanks to the Australian Institute of Marine Science for support during the preparation of this book. I also wish to acknowledge the stimulating discussions provided by many colleagues and members of the staff of the Institute. Thanks are also due to Christine Cansfield-Smith for accurate proofreading, and to Bartosz Massel and Steve Clarke who worked on the figures.

I thank Dr Tom Hardy (JCU) and Dr Derek Burrage (AIMS) for their review of chapters and invaluable suggestions.

I am especially grateful to my wife, Barbara, for her accurate and patient word processing, and for her support during the writing.

Townsville, August 1995

Stanislaw R. Massel 
This page is intentionally left blank 


\section{Contents}

1 Introduction 1

1.1 Waves in the ocean and their significance . . . . . . . . . 1

1.2 Basic assumptions on seawater and wave motion . . . . . . . . 3

1.2.1 Continuous fluid and water particle concept . . . . . . . 3

1.2.2 Properties of seawater and its motion . . . . . . . . 4

1.3 Methods of description of random waves ........... . . 6

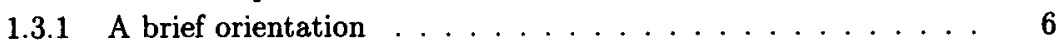

1.3.2 Basic definitions and concepts of time series analysis $\ldots \ldots 8$

1.3.3 Fundamentals of spectral description of ocean waves . . . . . 10

1.3.3.1 Deterministic description of wave train . . . . . . . 10

1.3.3.2 Second-order stochastic process . . . . . . . . 13

1.3.3.3 Wiener-Khinchine Theorem ............ 15

1.3.3.4 Cross-spectral density function . . . . . . . . 19

2 Generation of Waves by Wind $\quad 21$

2.1 Introduction . . . . . . . . . . . . . . 21

2.2 Airflow over sea surface . . . . . . . . . . . . . . . . 23

2.2.1 Atmospheric boundary layer above water . . . . . . . . 23

2.2.2 Similarity laws for drag coefficient $\mathbf{C}_{\mathbf{z}}$ and roughness length $\mathbf{z}_{\mathbf{0}} \quad 26$

2.2 .3 Practical applications . . . . . . . . . . . . . . . . . . 29

2.3 Similarity laws for wind-induced waves . . . . . . . . . . . 33

2.4 Wave generation models . . . . . . . . . . . . . 36

2.4 .1 Jeffreys' mechanism of wave generation . . . . . . . . . . 36

2.4.2 Basic results of the Phillips-Miles model . . . . . . . . 38

2.4.3 Resonance type model in water of finite depth . . . . . . . 43

2.4 .4 Resonance type model with dissipation . . . . . . . . . 47

2.4 .5 Inclusion of fluctuation of tangential stresses . . . . . . . 50

2.4.6 Inclusion of airflow turbulence in the Miles' model . . . . . . 52

2.4 .7 Effect of wind-generated waves on airflow . . . . . . . . 53

2.4.8 Wind-current coupling in gravity-capillary wave generation model 55

2.5 Wave energy balance in spectral form . . . . . . . . . . . . 57 
3 Spectral Properties of Ocean Waves $\quad 63$

3.1 Introduction . . . . . . . . . . . . . . . . . . 63

3.2 Frequency spectra of ocean waves . . . . . . . . . . . . . . 64

3.2.1 Spectral moments and spectral width . . . . . . . . . . . 64

3.2 .2 Spectrum shape . . . . . . . . . . . . . . . . 69

3.2.2.1 Saturation range . . . . . . . . . . . . . 69

3.2.2.2 Typical frequency spectra . . . . . . . . . . . . . 79

3.2.3 Higher order spectra . . . . . . . . . . . . . . . . . 92

3.2.4 Dispersion relation for ocean waves . . . . . . . . . . . . 95

3.3 Directional spectral functions . . . . . . . . . . . . . . . . . . 99

4 Statistical Properties of Ocean Waves 109

4.1 Introduction . . . . . . . . . . . . . . . . . . 109

4.2 Surface displacement . . . . . . . . . . . . . . . . 110

4.2.1 Probability distribution of surface displacement . . . . . . . . 110

4.2.2 Distribution of nonlinear wave surface displacements . . . . . 114

4.2.3 Extreme surface displacements . . . . . . . . . . . . . . . . 118

4.2.3.1 Probability distribution for positive and negative maxima ................... 118

4.2.3.2 Structure of extreme waves . . . . . . . . . 124

4.2.4 Influence of wave breaking on probability distribution of surface displacement in deep water . . . . . . . . . . . . . . . . . . 127

4.2.5 Probability distribution of surface displacement in finite water

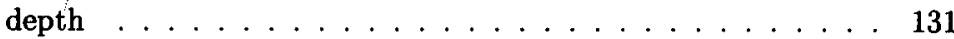

4.3 Wave height ..................... . . . . . . . . . . . . . . . .

4.3.1 Próbability distribution of wave height for a narrow-band spectrum ..................... . . 136

4.3.2 Influence of wave nonlinearity on wave height distribution . . 142

4.3.2.1 Modification of the Rayleigh distribution . . . . . . . 142

4.3.2.2 Crest-to-trough wave height distribution . . . . . . . 145

4.3.2.3 Probability distribution of large wave heights . . . . 148

4.3.2.4 Influence of second order nonlinearities . . . . . . . 150

4.3.3 Influence of wave breaking on wave height distribution in deep water . . . . . . . . . . . . . . . 153

4.3.4 Probability distribution of extreme wave height . . . . . . 155

4.3.5 Probability distribution of wave height in finite water depth . 160

4.3.6 Probability distribution of wave height in a surf zone . . . . . 164

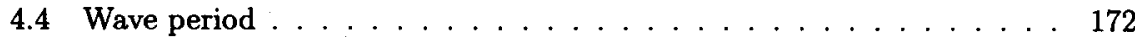

4.4.1 Joint distribution of wave heights and periods . . . . . . . . . 172

4.4.2 Probability distribution of wave period ........... 176

4.5 Wave orbital velocities and pressure . . . . . . . . . . . . . . . . 180

4.5.1 Probability distribution of orbital velocities and pressure . . . 180 
4.5.2 Influence of intermittence effect on probability distribution of orbital velocities and pressure near water level . . . . . . . . . 188

4.6 Wave group statistics . . . . . . . . . . . . . . . . . . . . 192

4.6.1 Level-crossing problem . . . . . . . . . . . . . . . 194

4.6.2 Markov chain representation . . . . . . . . . . . . . . . 198

5 Prediction of Ocean Waves in Deep Water 201

5.1 Introduction . . . . . . . . . . . . . . . . 201

5.2 Basic wave processes in deep water . . . . . . . . . . . . . 202

5.2.1 Atmospheric forcing ................ . 203

5.2.2 Nonlinear interaction between wave components . . . . . . . 209

5.2.2.1 Evaluation of nonlinear energy transfer . . . . . . . 209

5.2.2.2 Parameterization of nonlinear energy transfer . . . . 214

5.2.2.3 Nonlinear coupling between swell and wind waves . . 216

5.2.3 Energy dissipation due to white capping . . . . . . . . . . 218

5.2.4 Energy balance for fully-developed and growing seas . . . . . . 220

5.3 Wave prediction models . . . . . . . . . . . . . . . . . . 222

5.3.1 Wave models based on energy transfer equation . . . . . . 223

5.3.1.1 First generation wave models . . . . . . . . . . . . 223

5.3.1.2 Second generation wave models . . . . . . . . . 225

5.3.1.3 Third generation wave models . . . . . . . . . . . 231

5.3.2 Empirical prediction models . . . . . . . . . . . . . 235

5.3.2.1 Fetch- and time-limited wave growth . . . . . . . 235

5.3.2.2 JONSWAP prediction graphs . . . . . . . . . . 237

5.3.2.3 SPM prediction graphs.............. 239

5.3.2.4 SMB prediction graphs . . . . . . . . . . . 241

5.3.2.5 Donelan method ............... 241

5.3.2.6 Krylov method ... . . . . . . . . . . . 243

5.3.2.7 Comparison of empirical prediction methods . . . . 251

6 Prediction of Ocean Waves in Shallow Water 255

6.1 Introduction . . . . . . . . . . . . . . . 255

6.2 Basic wave processes in shallow water . . . . . . . . . . 256

6.2.1 Wave refraction due to bottom shoaling . . . . . . . . . . 256

6.2.2 Refraction by currents in a shoaling water depth . . . . . . . 264

6.2.2.1 Propagation of random waves in an inhomogeneous region .................. . 264

6.2.2.2 Influence of uniform current on a saturation range spectrum ................ . . 269

6.2.3 Combined refraction and diffraction ............ 271

6.2 .4 Reflection of ocean waves . . . . . . . . . . . . . 275

6.2.5 Nonlinear interaction between spectral wave components . . . 284 
6.2.5.1 Narrow-band spectrum approximation . . . . . . . 284

6.2.5.2 Stokes' perturbation technique . . . . . . . . . . 285

6.2.6 The largest wave height in water of constant depth . . . . 291

6.2.6.1 Experimental data . . . . . . . . . . . . . . . 291

6.2.6.2 Regular waves. . . . . . . . . . . . . . . . . 292

6.2.6.3 Irregular waves . . . . . . . . . . . . . . . 303

6.2.7 Wave energy dissipation at sea bottom . . . . . . . . 306

6.2.7.1 A brief orientation . . . . . . . . . . . . 306

6.2.8 Energy dissipation due to bottom friction . . . . . . . . . 306

6.2.9 Energy dissipation due to bottom permeability . . . . . . . . 308

6.2.9.1 Energy dissipation due to soft mud . . . . . . . . 311

6.2.10 Energy dissipation due to wave breaking . . . . . . . . 315

6.2.10.1 Periodic bore approach . . . . . . . . . . . 316

6.2.10.2 Energy flux difference model . . . . . . . . . . . 321

6.2 .10 .3 Local water depth model . . . . . . . . . . . . . . 322

6.2.10.4 Surface roller concept . . . . . . . . . . . . 323

6.3 Wave prediction models . . . . . . . . . . . . . . . . . 324

6.3.1 Models based on energy transfer equation . . . . . . . . . 324

6.3.1.1 First generation wave models . . . . . . . . . . . 324

6.3.1.2 Second generation wave models . . . . . . . . . 325

6.3.1.3 Third generation wave models . . . . . . . . . . . 327

6.3.1.4 Wave prediction in very shallow water . . . . . . 328

6.3.2 Empirical prediction models . . . . . . . . . . . . . 330

6.3.2.1 SPM prediction method . . . . . . . . . . . . 330

6.3.2.2 Krylov prediction method . . . . . . . . . . 334

7 Waves at Islands and Coral Reefs $\quad 337$

7.1 Introduction . . . . . . . . . . . . . . . . . . 337

7.2 Propagation of waves over steep bottom slopes . . . . . . . . . 337

7.2.1 Geometrical optics and mild-slope approximations . . . . . . 337

7.2.2 Application of extended refraction-diffraction equation . . . 339

7.2.2.1 Non-breaking waves . . . . . . . . . . . . . 339

7.2.2.2 Breaking waves . . . . . . . . . . . . 343

7.2.2.3 Wave set-down and set-up . . . . . . . . . . 345

7.2.2.4 Numerical examples and comparison with experiments 346

7.3 Maximum wave height on shoal (reef) flat . . . . . . . . . . 350

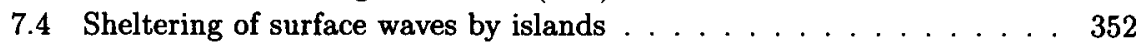

7.4.1 A brief orientation . . . . . . . . . . . . . 352

7.4.2 Scattering of waves by an isolated steep conical island . . . . 352

7.4.2.1 Pure refraction solution . . . . . . . . . . . 354

7.4.2.2 Refraction-diffraction solution with dissipation . . . . 355

7.4.3 Scattering of waves by a group of islands . . . . . . . . 357 
7.5 Prediction of waves on island (reef) archipelagoes . . . . . . 358

7.6 Interaction of waves with coral reef bottoms . . . . . . . . . . 359

7.6 .1 Forces on coral . . . . . . . . . . . . . 360

7.6 .2 Velocity field around coral . . . . . . . . . . 366

7.6.3 Probability of coral dislodgement or persistence . . . . . . 367

8 Long-Term Statistics for Ocean Surface Waves 369

8.1 Introduction . . . . . . . . . . . . . . . 369

8.2 Visual observations of wave heights . . . . . . . . . . . 369

8.3 Visual observations versus instrumental data . . . . . . . . . 372

8.4 Visual observations of wave periods . . . . . . . . . . . 373

8.5 Long-term distributions of wave heights . . . . . . . . . . . . 374

8.5.1 The initial probability distribution is unknown . . . . . . 375

8.5.2 Probability distributions of extreme waves . . . . . . . 381

8.6 Estimation of distribution parameters . . . . . . . . . . 386

8.7 Goodness of fit tests and confidence intervals . . . . . . . . . 386

8.8 Design wave selection . . . . . . . . . . . . . . . . 387

8.9 Geography of waves $\ldots \ldots \ldots \ldots \ldots \ldots$

8.9 .1 A brief orientation . . . . . . . . . . . 388

8.9 .2 Atlantic Ocean . . . . . . . . . . . . . . 390

8.9 .3 Pacific Ocean . . . . . . . . . . . . . . . . 391

8.9 .4 Indian Ocean . . . . . . . . . . . . . . . . . 392

8.9.5 Examples of wave climate in various seas . . . . . . . . 394

9 Measurement, Simulation and Data Processing 395

9.1 Introduction . . . . . . . . . . . . . . . . . . . 395

9.2 A single point wave data . . . . . . . . . . . . . . 395

9.2.1 Measurement techniques . . . . . . . . . . . 395

9.2.1.1 Laboratory wave measurement . . . . . . . . . 395

9.2.1.2 Field wave measurements . . . . . . . . . . 398

9.2.2 Determination of spectral characteristics of surface waves . . . 399

9.2.2.1 Data sampling . . . . . . . . . . . . . . 399

9.2.2.2 Standardization of data, trend removal and filtering . 401

9.2.2.3 Calculation of frequency spectra . . . . . . . . 402

9.2.3 Calculation of statistical characteristics of waves . . . . . . 406

9.3 Measurement of wave directionality . . . . . . . . . . . 407

9.3.1 Measurement techniques . . . . . . . . . . . . . 407

9.3.2 Determination of directional wave spectra . . . . . . . 408

9.3.2.1 Fourier Expansion Method . . . . . . . . . . . 408

9.3.2.2 Maximum Entropy Method . . . . . . . . . . 411

9.3.2.3 Maximum Likelihood Method . . . . . . . . . . 416

9.3.2.4 Comparison of various analytical techniques . . . . 417 
9.4 Remote sensing techniques . . . . . . . . . . . . . . 418

9.4 .1 A brief orientation . . . . . . . . . . . . . 418

9.4.2 Application of satellite altimetry . . . . . . . . . 419

9.4.3 Application of satellite Synthetic Aperture Radar . . . . . . 420

9.5 Numerical simulation techniques . . . . . . . . . . . . . . . 421

9.5.1 Time domain simulation with a random-phase structure $\ldots 422$

9.5.2 Frequency domain simulation by a random-phase structure . . 423

$\begin{array}{ll}10 \text { References } & 427\end{array}$

$\begin{array}{ll}\text { Symbols and Notation } & \mathbf{4 6 7}\end{array}$

$\begin{array}{ll}\text { Author index } & 475\end{array}$

$\begin{array}{ll}\text { Subject index } & 485\end{array}$ 